\title{
Assessment of pharmacological strategies for management of major depressive disorder and their costs after an inadequate response to first-line antidepressant treatment in primary care
}

\author{
Antoni Sicras-Mainar ${ }^{1}$, Jorge Maurino ${ }^{2^{*}}$, Luis Cordero ${ }^{2}$, Milagrosa Blanca-Tamayo ${ }^{3}$ and Ruth Navarro-Artieda ${ }^{4}$
}

\begin{abstract}
Background: The aim of the study was to determine the most common treatment strategies and their costs for patients with an inadequate response to first-line antidepressant treatment (AD) in primary care.

Method: A retrospective cohort study of medical records from six primary care centers was conducted. Adults with a major depressive disorder diagnosis, at least 8 weeks of AD treatment after the first prescription, and patient monitoring for 12 months were analyzed. Healthcare (direct cost) and non-healthcare costs (indirect costs; work productivity losses) were described.

Results: A total of 2,260 patients were studied. Forty-three percent of patients ( $N=965)$ presented an inadequate response to treatment. Summarizing the different treatment approaches: $43.2 \%$ were switched to another AD, $15.5 \%$ were given an additional $A D, A D$ dose was increased in $14.6 \%$, and $26.7 \%$ remained with the same antidepressant agent. Healthcare/annual costs were 451.2 Euros for patients in remission vs. 826.1 Euros in those with inadequate response, and productivity losses were 991.4 versus $1,842.0$ Euros, respectively $(p<0.001)$.

Conclusion: Antidepressant switch was the most common therapeutic approach performed by general practitioners in naturalistic practice. A delay in treatment change when no remission occurs and a significant heterogeneity in management of these patients were also found.
\end{abstract}

Keywords: Major depressive disorder, Remission, Primary care, First-line antidepressant treatment, Costs

\section{Background}

Major depressive disorder (MDD) is one of the most common mental diseases in the general population, with an estimated annual prevalence of 5.7\% [1]. MDD is a disabling disease that impairs health-related quality of life and causes an increase in healthcare resource utilization [2-6]. Some studies show that one third of costs are derived from healthcare and the highest are indirect costs associated to loss of work productivity $[3,5,6]$.

It is usually recommended that patients with MDD are initially treated in primary care $(\mathrm{PC})$ and approximately

\footnotetext{
* Correspondence: jorgealejandro.maurino@astrazeneca.com

${ }^{2}$ AstraZeneca Medical Department, Madrid, Spain

Full list of author information is available at the end of the article
}

$80 \%$ of them are managed in PC only [7-10]. There is limited information on the referral rates to mental health care and referral criteria. In a study conducted in Spain, 23\% of general practitioners (GPs) referred patients with major depression to the psychiatrist [11]. In a survey conducted by Villava and Caballero (2006) among more than 1,000 GPs in Spain, the mean referral rate was $24 \%$, being higher in physicians who reported poorer training and greater demand for care [12]. As regards referral criteria, the main reasons reported were severity of the episode (87\%), lack of response to treatment (41\%), and express request by the patient (37\%).

Regardless of which antidepressant (AD) is chosen, the final aim of therapy for MDD is to achieve a total remission of symptoms. Lack of remission has been associated with a higher risk of recurrences, more chronic

\section{() Biomed Central}

(c) 2012 Sicras-Mainar et al.; licensee BioMed Central Ltd. This is an Open Access article distributed under the terms of the Creative Commons Attribution License (http://creativecommons.org/licenses/by/2.0), which permits unrestricted use, distribution, and reproduction in any medium, provided the original work is properly cited. 
depressive episodes, a shorter duration between episodes, and a worse functioning [8,13-16]. Only few studies have directly measured the financial impact of MDD, showing that costs are significantly lower when patients achieved remission of symptoms $[3,5]$.

The introduction of newer-generation antidepressants has improved our ability to treat depression, although only $35-40 \%$ of patients will experience a remission of symptoms during an initial 8-week trial [17-19]. Four different pharmacologic approaches are available for treating patients who have experienced inadequate response to a first-line antidepressant: increasing the dose of the antidepressant, switching to a different antidepressant, combining the initial antidepressant with a second one, and augmenting the treatment with a nonantidepressant agent [20]. Definition of inadequate response is still controversial, but most experts define it as failure to achieve symptomatic remission [13,21,22].

The question of how to proceed with the next step in MDD treatment after an initially unsuccessful trial is crucial due to the diversity of therapeutic approaches available. The aim of the study was to determine the most common treatment strategies and their costs for patients with an inadequate response to first-line antidepressant in primary care.

\section{Methods}

\section{Study design and data extraction}

We carried out an observational, retrospective cohort study of medical records held by the health care provider, Badalona Serveis Assistencials (BSA). The study population consisted of patients from six primary health care centres managed by BSA. They cover a population of 120,000 inhabitants, mostly urban, middle-low socioeconomic status, and with a predominance of industrial workers.

Personal identification of patients was removed from the start, subsequently maintaining complete dissociation between patient identification and their clinical data, as requested by Spanish legislation protecting confidentiality of patient health data. Then, written consent was not required for this type of study. The study protocol was approved by the investigational review board of the Hospital Germans Trias i Pujol (Badalona, Spain; NCT01446692).

\section{Patients}

All patients who met the following characteristics were included in the study: (a) aged over 18; (b) a diagnosis of major depressive disorder according to the International Classification of Primary Care (ICPC-2, code P76), either as a single (incidence) or recurrent episode (prevalence, new episode) [23]; (c) antidepressant treatment started between January 1st, 2008 and December 31st, 2009; (d) prescription meeting the criteria for a minimum adequate treatment (at least 8 weeks of AD treatment since the first prescription); (e) inclusion in the long-term prescriptions program; (f) who had not received any antidepressant treatment within the previous 6 months; and (g) a patient follow-up during a subsequent initiation of treatment.

\section{Study groups and remission criteria}

Patients were divided into two study groups: a) patients with an inadequate response to first-line AD treatment (no remission), and b) patients in remission after the first AD treatment. Patients were followed up for the main outcome measures of the study at 6 and 12 months from the date of start of treatment. Patients were considered to be in remission when they had a Hamilton Depression Rating Scale (HDRS) total score $\leq 7$ points after at least 8 weeks of $\mathrm{AD}$ treatment in adequate doses $[24,25]$. Most patients completed the scale. However, the decision to change the intervention strategy was always at the physician's discretion. The HDRS is routinely performed among patients with depressive symptoms in our centers by GPs or nurses.

The following options were considered as potential strategies for a change of drug treatment: increasing the dose of $\mathrm{AD}$, change to a different $\mathrm{AD}$, combination with a second $\mathrm{AD}$, or association with a new drug without intrinsic antidepressant properties (augmentation) [20].

\section{Sociodemographic variables and comorbidity}

The main study variables were: age (continuous and by ranges) and sex, as well as personal history taken from the International Classification of Primary Care (ICPC-2) [23]. The following were used as summary variable for overall comorbidity for each patient seen: a) the Charlson Comorbidity Index as an approximation to patient severity [26] and b) the Case-mix Index, obtained from the Adjusted Clinical Groups (ACG), a system classifying patients by iso-resource consumption [27]. The algorithm of the Grouper $\mathrm{ACG}^{\circledR}$ Case-mix System consists of a number of consecutive steps until the 106 mutually exclusive ACG groups are obtained, one for each patient seen. The ACG application provides resource utilization bands (RUBs), so that each patient is grouped into one of the five mutually exclusive categories based on overall morbidity (1: healthy or with a very low morbidity, 2 : low morbidity, 3: moderate morbidity, 4: high morbidity, and 5: very high morbidity).

\section{Drugs prescribed, treatment compliance and persistence, and referrals}

Prescriptions of the following therapeutic classes and active ingredients for the central nervous system or psychoactive drugs were considered: ADs (N6A), antipsychotics and mood stabilizers (N5A), anxiolytic drugs (N5B), 
hypnotics and sedatives (N5C) of the ATC classification [28]. Compliance was defined as the extent of agreement of patient behavior with use of medication based on recommendations by healthcare professionals in charge of the patient. Compliance was estimated as the ratio between the total number of tablets dispensed and the total number of tablets recommended or prescribed, assuming that drug dispensing (purchase of medication at the pharmacy) does not represent actual consumption or intake, but is closely associated with this [29]. Treatment persistence was defined as the time in weeks without discontinuation of initial treatment or without switching to another medication at least 8 weeks after initial prescription. The number of and reasons for referrals to mental health care were analyzed.

Health and non-health care resources and cost estimation Direct healthcare costs (direct costs) were those related to care activity (medical visits, diagnostic or therapeutic requests, etc.) performed by professionals, while nonhealthcare or indirect costs were those related to work productivity losses. The productivity losses were calculated in terms of days off work [30]. The design of the cost system was defined taking into account the characteristics of the organization and the degree of development of the available information systems. The analytic unit serving as the basis for final calculation (during the study period) was the patient seen, and cost was expressed as mean cost per patient (cost/unit). The different study concepts and their economic assessment are detailed in Table 1 (year 2009). The different rates were obtained from analytical accounting of the centers, except for medication and days of sick leave. Prescriptions (acute, chronic, or demand medical prescriptions) were quantified based on the retail price by pack at the time of prescription. Days of disability for work were considered as non-healthcare costs (indirect costs). The cost was quantified based on the

Table 1 Details of unit costs of healthcare resources and work productivity losses

\begin{tabular}{lc}
\hline Healthcare and non-healthcare resources & Unit cost 2009 (Euros) \\
\hline Medical visits in primary care & 22.74 \\
Supplemental tests & 21.86 \\
Laboratory tests & 18.14 \\
Conventional radiology & 36.45 \\
Diagnostic/therapeutic tests & Retail price/pack \\
Drug prescription & \\
Work productivity-Indirect Costs & 79.61 \\
\hline Labor cost per day of sick leave* & \\
\hline Source of healtcare resources: own anatical accounting. *Source: INE-
\end{tabular}

Source of healthcare resources: own analytical accounting. *Source: INENational Institute of Statistics [31]. interprofessional minimum wage (source: Spanish Institute of Statistics- INE) [31].

\section{Statistical analysis}

A univariate descriptive statistical analysis was performed using the mean, standard deviation, and 95\% confidence intervals (CI). Normal data distribution was confirmed using a Kolmogorov-Smirnov test. A nonparametric Kaplan-Meier survival analysis was used to test treatment persistence (median time). ANOVA, Chi-square, and linear Pearson's correlation tests were used for bivariate analysis. To assess the association of related factors (variables) for each specific strategy, a multinomial logistic regression analysis was performed (procedure: main components). Cost comparison was performed in accordance to recommendations by Thompson and Barber, specifically on the comparison of average health care cost between the study groups [32]. For correction of the cost model was used the analysis of covariance (ANCOVA), with sex, age, comorbidity, and Charlson index as covariates (procedure: estimation of marginal means; Bonferroni correction). SPSSWIN version 17 software was used, and values of $\mathrm{p}<0.05$ were considered statistically significant.

\section{Results}

The number of patients $>18$ years screened was 83,370 , of whom $72,372(86.8 \%)$ requested care. Finally, 2,260 subjects who met the inclusion criteria were analyzed (Figure 1). Mean age was 58.8 years (74\% females), RUBs were 2.5 points, and mean number of comorbidities was 4.6 per patient. Dyslipidemia (43.6\%), high blood pressure (34.2\%), and fibromyalgia (25.2\%) were the most common comorbidities. Annual incidence (new cases) was $16.3 \%$ (95\% CI: $14.5-17.5 \%)$, with a cumulative incidence rate of $6.8 / 1,000$ inhabitants/year (95\% CI: 6.1-7.9/1,000 inhabitants/year).

Forty-three percent of patients $(\mathrm{N}=965 ; 95 \% \mathrm{CI}$ : $40.0 \%-46.4 \%$ ) presented an inadequate response to firstline $\mathrm{AD}$ treatment (during patients' follow-up period: 1 year). Patients without remission were older (61.0 vs. 57.1 years; $\mathrm{p}<0.001)$, females $(76.8 \%$ versus $71.9 \%$; $\mathrm{p}=0,009)$, and retired $(63.1 \%$ vs. $47.0 \% ; \mathrm{p}<0.001)$. These patients had higher mean values of general morbidity (5.3 vs. 4.1 episodes/year) and RUB/year (2.7 versus 2.4) (Table 2).

Summarizing the distribution of different treatment approaches for the management of inadequate $\mathrm{AD}$ initial response in naturalistic practice: $43.2 \%$ were switched to another AD (time elapsed: 6.5 months), 15.5\% were given an additional $\mathrm{AD}$ (time elapsed: 5.4 months), $\mathrm{AD}$ dose was increased in 14.6\% (time elapsed: 6.1 months), and $26.7 \%$ remained with the same antidepressant agent (Table 3). 


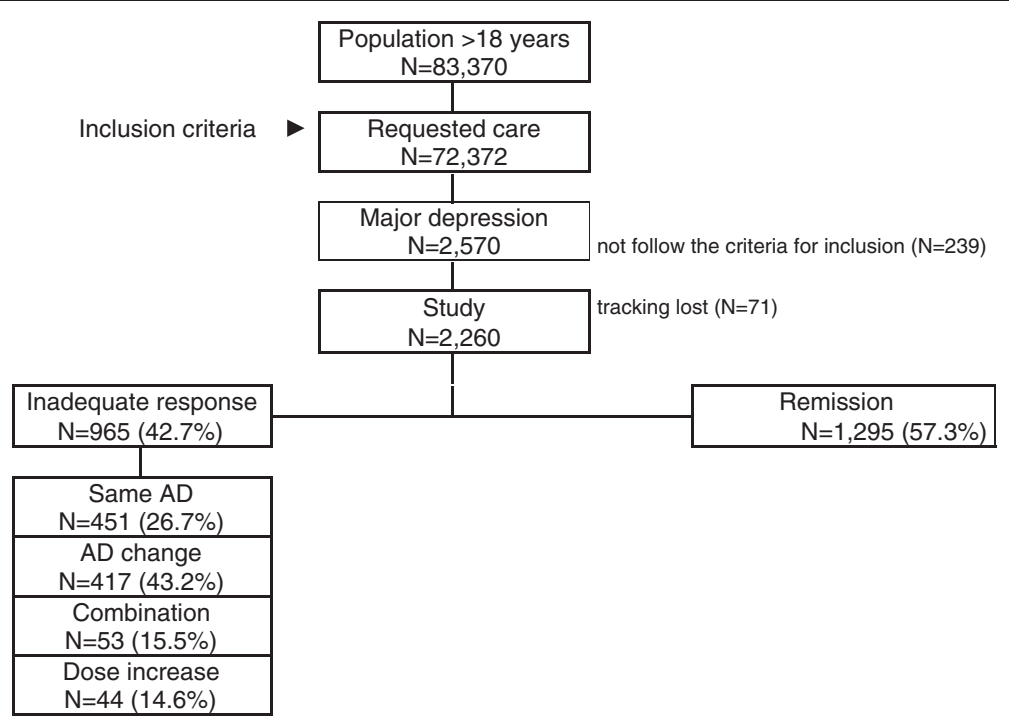

Figure 1 General study disposition. Years 2008-2009.

Patients with an inadequate $\mathrm{AD}$ response had worse percentages of treatment compliance $(65.1 \%$ versus $67.7 \%$; $\mathrm{p}<0.001)$ and treatment persistence at 12 months $(31.8 \%$ [95\% CI: $27.5 \%-35.9 \%$ versus $53.2 \%$ [95\% CI: $50.5 \%-$ $56.9 \%$; $\mathrm{p}<0.001)$. An acceptable correlation was found between treatment compliance and persistence $(r=0.692$; $\mathrm{p}<0.001$ ). Referral rate to mental health care was $18.8 \%$ (95\% CI: $17.2 \%-20.4 \%)$. The reasons were: inadequate response to treatment (47.5\%), disease severity $(42.1 \%)$ and patient's decision (10.4\%). In patients with remission, referral rate was lower $(16.8 \%$ versus $21.6 \%$; $<0.001)$ and time from start of treatment to referral was shorter (3.4 versus 6.4 months; $\mathrm{p}<0.001$ ), Figure 2 . Table 4 shows the relationship between treatment compliance and persistence, as well as referrals to psychiatry care.

Table 5 shows resource utilization and cost estimation (mean/unit/year) according to AD response. Patients with an inadequate $\mathrm{AD}$ response presented higher mean number of visits/year (16.8 vs $11.1 ; \mathrm{p}<0.001)$ and days of work disability (20.2 versus 12.8 days; $\mathrm{p}<0.001)$ compared with patients achieving remission. Total annual gross cost of patients demanding care during the 12 months of follow-up amounted to 4.3 million Euros. Healthcare (direct) costs and costs derived from work productivity losses (non-healthcare, indirect costs) represented $32.7 \%$ and $67.3 \%$ of total costs, respectively $(\mathrm{p}<0.001)$. Medical visits accounted for $16.3 \%$, drugs prescribed for $15.6 \%$, and diagnostic tests for $0.8 \%$. Mean cost per patient of gross direct costs by remission status (absence/presence) was 857.2 versus 443.2 Euros, $\mathrm{p}<0,001$. In the adjusted model, total costs were 2,668.1 Euros (95\%CI: 2,346.9-2,989.2) versus 1,442.6 Euros (95\%CI: 1,180.9-1,704.2), respectively; $\mathrm{p}<0.001$. Costs from work productivity losses were 1,842.0 versus 991.4
Euros, and healthcare (direct) costs were 826.1 versus 451.2 Euros, respectively; $\mathrm{p}<0.001$. These differences persisted in all cost components (gross and adjusted).

In general, patients undergoing no change in $\mathrm{AD}$ were incident cases (29.2\%), with low treatment compliance $(62.3 \%)$ and referral rate $(17.1 \%)$. Patients under a change to a new $\mathrm{AD}$ were prevalent cases $(81.5 \%)$ with longer disease duration (5.2 years) and referred to psychiatry care due to a lack of response to treatment (53.1\%). Patients receiving $\mathrm{AD}$ combination had a similar profile. Most of them $(90.1 \%)$ were prevalent cases with long disease duration (6.4 years). However, they showed a greater referral rate $(28.2 \%)$, mainly due to disease severity $(53.3 \%)$, and also have a higher mean healthcare cost (1,041.8 Euros). Patients in whom AD dose was increased were younger (52.9 years) and new cases (20.4\%), with high treatment compliance (69.2\%).

In the logistic regression model, predictors associated with lack of remission included: treatment noncompliance $(\mathrm{OR}=1.7 ; 95 \% \mathrm{CI}: 1.3-2.7)$, referral to a psychiatrist $(\mathrm{OR}=1.5$; 95\%CI: $1.3-1.8)$, years from disease onset $(\mathrm{OR}=1.2 ; 95 \% \mathrm{CI}$ : $1.1-1.3)$, age $(\mathrm{OR}=1.1 ; 95 \%$ CI: $1.0-1.3$ ), and presence of comorbidity (OR $=1.1 ; 95 \%$ CI: $1.0-1.2) ; \mathrm{p}<0.05$. No variable was associated with a greater probability to the type of strategy used.

\section{Discussion}

In our study, $42.7 \%$ of patients presented an inadequate response to first-line antidepressant treatment. AD switch was the most common therapeutic approach (43.2\%) performed by GPs after the lack of remission in daily clinical practice. Time until the change of strategy was extremely long (mean 6.5 months) and $26.7 \%$ of patients remained with the same initial AD. 
Table 2 Sociodemographic and clinical characteristics

\begin{tabular}{|c|c|c|c|c|}
\hline Groups & Inadequate response & Remission & Total & $P$ value \\
\hline Number of patients, $\%$ & $\mathrm{~N}=965(42.7 \%)$ & $\bar{N}=1,295(57.3 \%)$ & $\mathrm{N}=2,260$ & \\
\hline Mean age, years & $61.0(15.1)$ & $57.1(16.4)$ & $58.8(15.9)$ & $<0.001$ \\
\hline Ranges: $18-44$ years & $13.7 \%$ & $24.6 \%$ & $19.9 \%$ & $<0.001$ \\
\hline $45-64$ years & $46.1 \%$ & $42.6 \%$ & $44.1 \%$ & $<0.001$ \\
\hline $65-74$ years & $18.1 \%$ & $13.8 \%$ & $15.7 \%$ & $<0.001$ \\
\hline$>74$ years & $22.1 \%$ & $19.0 \%$ & $20.3 \%$ & $<0.001$ \\
\hline Gender, female & $76.8 \%$ & $71.9 \%$ & $74.0 \%$ & 0.009 \\
\hline Occupational status, retired & $63.1 \%$ & $47.0 \%$ & $53.9 \%$ & $<0.001$ \\
\hline Mean number of comorbidities & $5.3(3.5)$ & $4.1(3.3)$ & $4.6(3.4)$ & $<0.001$ \\
\hline Mean RUBs & $2.7(0.9)$ & $2.4(1.1)$ & $2.5(1.1)$ & $<0.001$ \\
\hline RUB-1 & $17.1 \%$ & $23.4 \%$ & $20.7 \%$ & $<0.001$ \\
\hline RUB-2 & $9.3 \%$ & $18.4 \%$ & $14.5 \%$ & $<0.001$ \\
\hline RUB-3 & $59.5 \%$ & $49.5 \%$ & $53.8 \%$ & $<0.001$ \\
\hline RUB-4 & $12.3 \%$ & $7.1 \%$ & $9.3 \%$ & $<0.001$ \\
\hline RUB-5 & $1.8 \%$ & $1.5 \%$ & $1.6 \%$ & $<0,001$ \\
\hline Mean Charlson index & $0.4(0.7)$ & $0.3(0.8)$ & $0.4(0.7)$ & NS \\
\hline \multicolumn{5}{|l|}{ Associated comorbidities } \\
\hline Arterial hypertension & $39.0 \%$ & $30.6 \%$ & $34.2 \%$ & $<0.001$ \\
\hline Diabetes mellitus & $17.1 \%$ & $12.9 \%$ & $14.7 \%$ & 0.005 \\
\hline Dyslipidemia & $49.7 \%$ & $39.1 \%$ & $43.6 \%$ & $<0.001$ \\
\hline Obesity & $22.3 \%$ & $18.7 \%$ & $20.2 \%$ & 0.035 \\
\hline Active smoking & $22.9 \%$ & $25.9 \%$ & $24.6 \%$ & NS \\
\hline Alcoholism & $4.2 \%$ & $4.4 \%$ & $4.3 \%$ & NS \\
\hline Ischemic heart disease & $7.0 \%$ & $3.7 \%$ & $5.1 \%$ & $<0.001$ \\
\hline Cerebrovascular events & $10.6 \%$ & $7.7 \%$ & $8.9 \%$ & 0.019 \\
\hline Cardiovascular events & $15.4 \%$ & $10.4 \%$ & $12.6 \%$ & $<0.001$ \\
\hline Organ insufficiency & $11.5 \%$ & $11.1 \%$ & $11.3 \%$ & NS \\
\hline Bronchial asthma. & $8.8 \%$ & $5.6 \%$ & $7.0 \%$ & $<0.001$ \\
\hline COPD & $4.2 \%$ & $3.2 \%$ & $3.6 \%$ & NS \\
\hline Neuropathies & $2.4 \%$ & $1.5 \%$ & $1.9 \%$ & NS \\
\hline Dementia (all types) & $4.9 \%$ & $3.2 \%$ & $3.9 \%$ & 0.032 \\
\hline Organic psychosis & $3.5 \%$ & $2.9 \%$ & $3.1 \%$ & NS \\
\hline Malignant tumors & $10.3 \%$ & $7.1 \%$ & $8.5 \%$ & 0.008 \\
\hline Fibromyalgia & $28.9 \%$ & $22.4 \%$ & $25.2 \%$ & $<0.001$ \\
\hline Time since MDD onset, years & $4.8(3.8)$ & $3.5(3.6)$ & $4.1(3.7)$ & $<0.001$ \\
\hline New, incident cases $(N=738)$ & $23.3 \%$ & $38.7 \%$ & $32.2 \%$ & $<0.001$ \\
\hline Prevalent cases $(\mathrm{N}=1,522)$ & $76.7 \%$ & $61.3 \%$ & $67.8 \%$ & $<0.001$ \\
\hline
\end{tabular}

RUBs: resource utilization bands (morbidity burden of patients); COPD: chronic obstructive pulmonary disease; MDD: major depressive disorder; values are given as percentage or mean (standard deviation); NS: not significant.

Patients were considered to be in remission when they had a Hamilton Depression Rating Scale total score $\leq 7$ points after at least 8 weeks of AD treatment in adequate doses $[24,25]$.

Previous studies focused on therapeutic adherence among patients with MDD showed that compliance was low, ranging from $25 \%$ to $50 \%$ [33-35]. In our study, patients achieving remission showed better rates of compliance $(67.7 \%$ vs. $65.1 \%)$ and treatment persistence
(53.2\% vs. $31.8 \%)$, respectively. Our results are clearly higher, possibly because of the indirect measurement method used [36]. Establishing and maintaining a supporting therapeutic relationship is crucial for ensuring compliance and symptom remission. Factors associated 
Table 3 Pharmacologic strategies

\begin{tabular}{|c|c|c|c|c|}
\hline Groups & Same $A D^{1}$ & AD change ${ }^{2}$ & Combination $^{3}$ & Dose increase $^{4}$ \\
\hline Number of patients, $\%$ & $\overline{\mathrm{N}=451(26.7 \%)}$ & $\bar{N}=417(43.2 \%)$ & $\overline{N=53(15.5 \%)}$ & $\bar{N}=44(14.6 \%)$ \\
\hline \multicolumn{5}{|l|}{ Time to change, months } \\
\hline Mean & - & $6.5(3.9)$ & $5.4(1.9)$ & $6.1(3.5)$ \\
\hline Median & - & 5.7 & 4.0 & 5.2 \\
\hline Mean age, years & $61.9(15.1)$ & $60.8(15.0)^{\star}$ & $61.1(15.4)$ & 52.9 (11.4), \\
\hline Gender, female & $75.4 \%$ & $77.2 \%$ & $83.1 \%$ & $79.5 \%$ \\
\hline \multicolumn{5}{|l|}{ Comorbidity } \\
\hline Mean number of episodes & $5.1(3.4)$ & $5.5(3.4)$ & $5.8(3.9)$ & $5.1(3.6)$ \\
\hline Mean RUBs & $2.7(0.9)$ & $2.7(0.9)$ & $2.8(1.0)$ & $2.5(1.0)$ \\
\hline Mean Charlson index & $0.4(0.7)$ & $0.5(0.7)$ & $0.4(0.6)$ & $0.3(0.7)$ \\
\hline Duration of MDD, years & $4.1(3.7)$ & $5.2(3.5)^{*}$ & $6.4(5.2)$ & $5.1(3.5)$ \\
\hline Incident cases $(\mathrm{N}=222)$ & $29.2 \%$ & $18.2 \%$ & $9.8 \%$ & $20.4 \% *$ \\
\hline Prevalent cases $(N=743)$ & $70.1 \%$ & $81.5 \%^{*}$ & $90.1 \%$ & $79.5 \%$ \\
\hline Treatment compliance & $62.3 \%$ & $67.1 \%$ & $64.8 \%$ & $69.2 \%$, \\
\hline Treatment persistence & $30.5 \%$ & $33.1 \%$ & $34.8 \%$ & $43.2 \%$, \\
\hline \multicolumn{5}{|l|}{ Referrals to psychiatry $(N=199)$} \\
\hline Referral rate & $17.1 \% *$ & $23.5 \%$ & $28.2 \%$ & $20.5 \%$ \\
\hline Mean referrals per patient & $0.2(0.4)$ & $0.2(0.5)$ & $0.3(0.5)^{*}$ & $0.2(0.5)$ \\
\hline Time to referral, months & $6.3(4.1)$ & $6.8(4.0)$ & $4.4(3.3)$ & $6.2(3.8)$ \\
\hline \multicolumn{5}{|l|}{ Reasons for referral } \\
\hline Disease severity $(N=82)$ & $39.0 \%$ & $39.8 \%$ & $53.3 \%{ }^{*}$ & $55.6 \%$, \\
\hline No response to treatment $(N=107)$ & $59.7 \%$ & $53.1 \%{ }^{*}$ & $33.3 \%$ & $44.4 \%$ \\
\hline Patient decision $(\mathrm{N}=10)$ & $1.3 \%$ & $7.1 \%$ & $13.3 \%$ & $0.8 \%$ \\
\hline \multicolumn{5}{|l|}{ Cost model (euro) } \\
\hline Healthcare costs & 782.1 & 901.4 & $1,041.8$ & 984.9 \\
\hline Non-healthcare costs (productivity) & $1,392.4$ & $1,710.6$ & $1,631.3$ & $1,978.1$ \\
\hline Total costs & $2,174.4$ & $2,612.0$ & $2,673.1$ & $2,963.1$ \\
\hline
\end{tabular}

RUBs: resource utilization bands; values given as percentage or mean (standard deviation); statistical significance: ${ }^{\dagger} \mathrm{p}<0.05$ for comparisons between each type of strategy versus the total group with no remission (significance tests: Chi-square and ANOVA; use of post hoc tests). $\mathrm{N}=965$.

1 Same treatment: no changes made in 12 months.

${ }^{2}$ Antidepressant change.

${ }^{3}$ Association to another antidepressant.

${ }^{4}$ Increase in antidepressant dose.

to non-adherence to $\mathrm{AD}$ treatment could include lack of information, misguided ideas about mental diseases, lack of family support, cognitive impairment, adverse reactions and side effects, and/or deficient physician-patient communication. Treatment should undoubtedly include, in addition to pharmacologic treatment, individualized interventions with educational and behavioral components [35].

The referral rate to mental health care was $18.8 \%$, mainly due to inadequate response to treatment and disease severity. Kendrick et al. reported an overall $22.8 \%$ rate of referrals to a psychologist or psychiatrist, as compared to the $25 \%$ and $38 \%$ rates reported by Wang and Grembowski, respectively [37-39]. These differences are probably the result of the different factors involved (training of professionals, psychiatric comorbidities, organizational models, resources availability) $[40,41]$.

The most commonly used active ingredients were paroxetine, fluoxetine, sertraline, and citalopram, all of them belonging to the selective serotonin reuptake inhibitors class. These are the antidepressants recommended as first-line treatment in current international guidelines $[8,10,14,15]$.

The different morbidity burdens found in the two groups may have an impact on total costs of the disease. Beyond methodological differences, the results were similar to those of other reviewed studies, although other European investigators have also confirmed their impact by measuring quality of life in these patients $[3,5,42,43]$. In our study, direct and indirect costs 


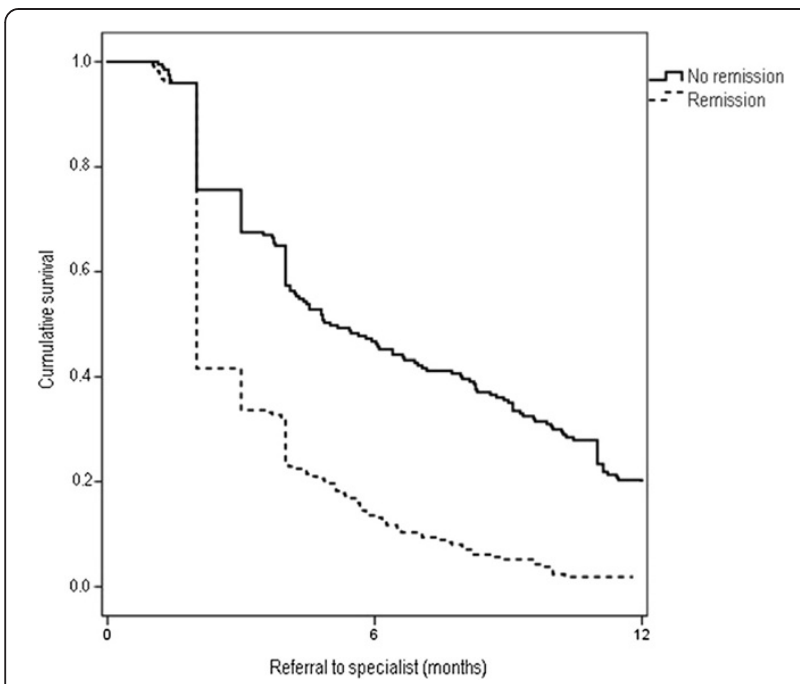

Figure 2 Survival curves of time elapsed to psychiatric referral (B) according to antidepressant response.

represented $32.7 \%$ and $67.3 \%$ of total costs, respectively. This distribution is similar to that reported in PC populations in Sweden and Spain, where indirect costs reached $65 \%$ of total costs $[5,44]$.

Data related to the different treatment approaches used after an inadequate response to first-line antidepressant treatment, especially in a primary care setting, is one of the strengths of this study. One aspect of these results related to the attitude of GPs which disagree with recommendations in clinical practice guidelines should be stressed: a significant number of patients continued on the same treatment despite not achieving remission. A recent publication by Chang et al. (2012) also found little active management among depressed patients treated in primary care centers in USA [45]. GPs were not more likely to adjust therapy, even when feedback regarding their patients' symptoms indicated an inadequate response. The STAR-D study showed that patients with longer depressive episodes were less likely to achieve remission [46]. After two treatment steps, it appears that over $50 \%$ of patients will achieve remission if they stay in treatment (i.e.,36.8\% step 1 plus $30.6 \%$ of the remaining $63.2 \%$ of patients). Thereafter, the chances of subsequent remission are much lower [46]. Guidelines of scientific associations for the treatment of patients with MDD recommend that, when remission is not achieved with an $\mathrm{AD}$ after 6 to 8 weeks of treatment at adequate dose, this should be changed [10]. However, controversy remains and there are no conclusive data as to which is the best alternative available $[19,47,48]$.

The article has several limitations inherent to studies based on population databases, such as disease underreporting or potential variability of professionals in routine use of the different clinical screening scales $[49,50]$. In addition, the most severe cases were possibly not included in the study because they are usually seen at mental health centers. Potential bias may have resulted from the fact that no consideration was given to the presence or absence of psychotherapeutic interventions in the course of disease. The only direct costs considered were those relating to the public health system and the area of influence of the patient. Sick leaves may in turn

Table 4 Relationship between compliance, persistence, and referrals to mental health care. Annual follow-up

\begin{tabular}{|c|c|c|c|c|}
\hline Groups & Inadequate response & Remission & Total & $P$ value \\
\hline Number of patients, $\%$ & $\mathrm{~N}=965(42.7 \%)$ & $\bar{N}=1,295(57.3 \%)$ & $\mathrm{N}=2,260$ & \\
\hline \multicolumn{5}{|l|}{ Treatment compliance } \\
\hline At 6 months & $66.2 \%$ & $67.9 \%$ & $67.1 \%$ & 0.033 \\
\hline At 12 months & $65.1 \%$ & $67.7 \%$ & $66.6 \%$ & $<0.001$ \\
\hline \multicolumn{5}{|l|}{ Treatment persistence } \\
\hline At 6 months & $46.5 \%$ & $64.4 \%$ & $53.9 \%$ & $<0.001$ \\
\hline At 12 months & $31.8 \%$ & $53.2 \%$ & $42.7 \%$ & $<0.001$ \\
\hline \multicolumn{5}{|l|}{ Referrals to psychiatry } \\
\hline Mean referrals (per patient) & $0.2(0.4)$ & $0.1(0.4)$ & $0.2(0.4)$ & 0.005 \\
\hline At 6 months $(N=293)$ & $4.8 \%$ & $8.2 \%$ & $13.1 \%$ & $<0.001$ \\
\hline At 12 months $(\mathrm{N}=413)$ & $21.6 \%$ & $16.8 \%$ & $18.8 \%$ & $<0.001$ \\
\hline Time to referral, months & $6.4(4.0)$ & $3.4(2.4)$ & $4.8(3.6)$ & $<0.001$ \\
\hline \multicolumn{5}{|l|}{ Reasons for referral } \\
\hline Disease severity $(N=174)$ & $41.2 \%$ & $43.0 \%$ & $42.1 \%$ & $<0.001$ \\
\hline No response to treatment $(N=196)$ & $53.8 \%$ & $41.6 \%$ & $47.5 \%$ & $<0.001$ \\
\hline Patient decision $(\mathrm{N}=43)$ & $5.0 \%$ & $15.4 \%$ & $10.4 \%$ & $<0.001$ \\
\hline
\end{tabular}

Values given as mean (standard deviation). Treatment compliance: ratio between the numbers of tablets dispensed/prescribed. Persistence: median time without discontinuation of initial treatment or without switch to another medication, at least 8 weeks after initial prescription. 
Table 5 Use of resources and total cost

\begin{tabular}{|c|c|c|c|c|}
\hline Groups & Inadequate response & Remission & Total & $P$ value \\
\hline Number of patients, $\%$ & $\mathrm{~N}=965(42.7 \%)$ & $\mathrm{N}=1,295(57.3 \%)$ & $\bar{N}=2,260(100 \%)$ & \\
\hline \multicolumn{5}{|l|}{ Use of resources } \\
\hline Medical visits & $16.8(9.1)$ & $11.1(8.2)$ & $13.6(8.9)$ & $<0.001$ \\
\hline Laboratory tests: & $0.6(0.8)$ & $0.5(0.7)$ & $0.5(0.8)$ & $<0.001$ \\
\hline Supplemental tests & $0.1(0.4)$ & $0.1(0.3)$ & $0.1(0.3)$ & NS \\
\hline Referrals & $0.2(0.4)$ & $0.1(0.4)$ & $0.2(0.4)$ & 0.005 \\
\hline Work productivity losses (days) & $20.2(63.7)$ & $12.8(45.5)$ & $16.1(54.2)$ & 0.001 \\
\hline \multicolumn{5}{|l|}{ Uncorrected cost model (Euros) } \\
\hline - Healthcare costs & 857.2 & 443.2 & 620.0 & $<0.001$ \\
\hline Medical visits & 383.9 & 253.7 & 309.3 & $<0.001$ \\
\hline Laboratory tests: & 15.0 & 10.3 & 12.3 & $<0.001$ \\
\hline Supplemental tests & 4.3 & 2.2 & 3.1 & $<0.001$ \\
\hline Drugs & 453.9 & 177.1 & 295.3 & $<0.001$ \\
\hline - Non-healthcare costs (productivity) & $1,615.3$ & $1,021.5$ & $1,275.1$ & 0.001 \\
\hline Total cost & $2,472.5$ & $1,464.8$ & $1,895.0$ & $<0.001$ \\
\hline Corrected cost model (Euros)* & & & Difference & \\
\hline Healthcare costs & 826.1 & 451.2 & 374.85 & $<0.001$ \\
\hline $95 \% \mathrm{Cl}$ & $798.5-853.5$ & $428.8-473.6$ & & \\
\hline Non-healthcare costs (productivity) & $1,842.0$ & 991.4 & 850.64 & $<0.001$ \\
\hline $95 \% \mathrm{Cl}$ & $1,525.7-2,158.3$ & $733.6-1249.1$ & & \\
\hline Total cost & $2,668.1$ & $1,442.6$ & $1,225.49$ & $<0.001$ \\
\hline $95 \% \mathrm{Cl}$ & $2,346.9-2,989.2$ & $1,180.9-1,704.2$ & & \\
\hline
\end{tabular}

Values are given as mean (standard deviation); p: statistical significance; Cl: confidence interval; Referrals were not considered in the calculation of health costs. $\left.{ }^{*}\right)$ ANCOVA model: each F test contrasts the simple effect of the presence of remission on each combination of levels of the other effects shown. These tests are based on pairwise, linearly independent comparisons between the estimated marginal means. Random components: remission status and sex; covariates: comorbidity and age.

be a limited indicator of indirect costs because it underestimates self-employment, and does not take unpaid work into account.

\section{Conclusions}

Our findings demonstrate that the therapeutic strategy most commonly used by GPs for the management of patients with MDD and an inadequate response to firstline treatment is switching to a different antidepressant drug. In addition, there was a significant delay in change of strategy.

Nowadays, symptomatic remission is the main goal in the management of major depressive disorder. Therefore, clinicians should carefully reevaluate patients presenting partial response to AD treatment and to adopt a faster change of pharmacological strategy.

\section{Competing interests}

This study was sponsored by AstraZeneca Spain. ASM and MBT are employees of BSA, the health provider which owned the database which was the subject of this study. JM and LC are employees of AstraZeneca. RNA has no conflicts of interests to declare.

\section{Authors' contributions}

This was a collaborative work and the authors worked closely each other. All authors participated in the design of the original study or in the interpretation and analysis of data and all of them drafting and have approved the final version of the manuscript. All authors were responsible for literature review and extraction of references, and also for taking the decision to submit the paper for publication.

\section{Author details}

'Dirección de Planificación, Badalona Serveis Assistencials SA, Badalona, Spain. ${ }^{2}$ AstraZeneca Medical Department, Madrid, Spain. ${ }^{3}$ Department of Psychiatry, Badalona Serveis Assistencials SA, Badalona, Spain. ${ }^{4}$ Department of Medical Information, Hospital Germans Trias i Pujol, Badalona, Spain.

Received: 30 May 2012 Accepted: 30 July 2012

Published: 3 August 2012

\section{References}

1. Wittchen HU, Jacobi F, Rehm J, Gustavsson A, Svensson M, Jönsson B, Olesen J, Allgulander C, Alonso J, Faravelli C, Fratiglioni L, Jennum P, Lieb R, Maercker A, van Os J, Preisig M, Salvador-Carulla L, Simon R, Steinhausen $\mathrm{HC}$ : The size and burden of mental disorders and other disorders of the brain in Europe 2010. Eur Neuropsychophamacol 2011, 21:655-679.

2. Simon GE, Chrisholm D, Treglia M, Bushnell D, LIDO group: Course of depression, health services costs, and work productivity in an international primary care study. Gen Hosp Psychiatr 2002, 24:328-335.

3. Sobocki P, Ekman M, Agren H, Runeson B, Jönsson B: The mission is remission: health economic consequences of achieving full remission 
with antidepressant treatment for depression. Int J Clin Pract 2006, 60:791-798.

4. Sicras-Mainar A, Navarro Artieda R, Rejas Gutiérrez J, Fernández de Bobadilla $\mathrm{J}$ : Comorbidity and related costs as a burden in the treatment of outpatients with depressive disorders in a primary care setting. Farm Hosp 2007, 31:101-105.

5. Sicras-Mainar A, Blanca-Tamayo M, Gutiérrez-Nicuesa L, Salvatella-Pasant J, Navarro-Artieda R: Impact of morbidity, resource use and costs on maintenance of remission of major depression in Spain: a longitudinal study in a population setting. Gac Sanit 2010, 24:13-19.

6. Salvador-Carulla L, Bendeck M, Fernandez A, Alberti C, Sabes-Figueroa R, Molina C, Knapp M: Costs of depression in Catalonia (Spain). J Affect Disord 2011, 132:130-138.

7. Grandes G, Montoya I, Arietaleanizbeaskoa MS, Arce V, Sanchez A, MAS Group: The burden of mental disorders in primary care. Eur Psychiatr 2011, 26:428-435.

8. Depression: the treatment and management of depression in adults (update, 2009): NICE: National Collaborating Centre for Mental Health commissioned by the National Institute for Health and Clinical Excellence. Available at: http://www.nice.org.uk/CG90.

9. Aragonès E, Piñol JL, Folch $S$, Labad A, Folch $S$, Mèlich N: Detection and management of depressive disorders in primary care in Spain. Int J Psychiatr Med 2004, 34:331-343.

10. Piek $E$, van der Meer K, Nolen WA: Guideline recommendations for longterm treatment of depression with antidepressants in primary care-a critical review. Eur J Gen Pract 2010, 16:106-112.

11. Espinosa-Sabina L, Castilla-Pérez MP: Estudio descriptivo de las derivaciones urgentes a una unidad de salud mental. Rev Asoc Esp Neuropsia 2002, 83:111-123.

12. Villava $E$, Caballero L: Study on use and follow-up of treatment with antidepressants conducted by Primary Care physicians. SEMERGEN 2006 32:427-432.

13. Keller MB: Past, present and future directions for defining optimal treatment outcome in depression: remission and beyond. JAMA 2003, 289:3152-3160.

14. Anderson IM, Ferrier IN, Baldwin RC, Cowen PJ, Howard L, Lewis G, Matthews K, McAllister-Williams RH, Peveler RC, Scott J, Tylee A: Evidencebased guidelines for treating depressive disorders with antidepressants: A revision of the 2000 British Association for Psychopharmacology guidelines. J Psychopharmacol 2008, 22:343-396.

15. Lam RW, Kennedy SH, Grigoriadis S, McIntyre RS, Milev R, Ramasubbu R, Parikh SV, Patten SB, Ravindran AV: Canadian Network for Mood and Anxiety Treatments (CANMAT) Clinical guidelines for the management of major depressive disorder in adults. III. Pharmacotherapy. J Affect Disord 2009, 117:S26-S43.

16. Rizvi AJ, Kennedy SH: The keys to improving depression outcomes. Eur Neuropsychopharmacol 2011, 21:S694-S702.

17. Cain RA: Navigating the Sequenced Treatment Alternatives to Relieve Depression (STAR*D) study: practical outcomes and implications for depression treatment in primary care. Prim Care 2007, 34:505-519.

18. Sinyor $M$, Schaffer $A$, Levitt $A$ : The sequenced treatment alternatives to relieve depression (STAR*D) trial: a review. Can J Psychiatr 2010, 55:126-135.

19. Connolly KR, Thase ME: If at first you don't succeed. A review of the evidence for antidepressant augmentation, combination and switching strategies. Drugs 2011, 71:43-64.

20. Papakostas Gl: Managing partial response or nonresponse. Switching, augmentation, and combination strategies for major depressive disorder. J Clin Psychiatr 2009, 70(suppl 6):16-25

21. Zimmernan M, McGlinchey JB, Posternak MA, Friedman M, Attiullah N, Boerescu D: How should remission from depression be defined? The depressed patient's perspective. Am J Psychiatry 2006, 163:148-150

22. Romera I, Perez V, Menchon JM, Polavieja P, Gilaberte I: Optimal cutoff point of the Hamilton Rating Scale for Depression according to normal levels of social and occupational functioning. Eur Psychiatr 2011, 186:133-137.

23. Lamberts $\mathrm{H}$, Wood M, Hofmans-Okkes IM: The International Classification of Primary Care in the European Community. With a multi-language layer. Oxford: Oxford University Press; 1993.

24. Frank E, Prien RF, Jarrett RB, Keller MB, Kupfer DJ, Lavori PW, Rush AJ, Weissman MM: Conceptualization and rationale for consensus definitions of terms in major depressive disorder. Remission, recovery, relapse, and recurrence. Arch Gen Psychiatry 1991, 48:851-855.

25. Uher R, Mors O, Rietschel M, Rajewska-Rager A, Petrovic A, Zobel A, Henigsberg N, Mendlewicz J, Aitchison KJ, Farmer A, McGuffin P: Early and delayed onset of response to antidepressants in individual trajectories of change during treatment of major depression: a secondary analysis of data from the Genome-Based Therapeutic Drugs for Depression (GENDEP) study. J Clin Psychiatr 2011, 72:1478-1484.

26. Charlson ME, Pompei P, Ales KL, MacKenzie CR: A new method of classifying prognostic comorbidity in longitudinal studies: development and validation. J Chronic Dis 1987, 40:373-383.

27. Johns Hopkins Bloomberg School of Public Health: The Johns Hopkins ACG ${ }^{\circledR}$ Case-mix System version 7.0-April, 2005. Baltimore: 2005.

28. The Anatomical Therapeutic Chemical Classification System with Defined Daily Doses (ATC/DDD): World Health Organization. Available at: http://www. who.int/classifications/atcddd/en/

29. Sackett DL, Haynes RB, Gibson ES: Randomized clinical trial of strategies for improving medication compliance in primary hypertension. Lancet 1975, 1:1205-1207.

30. Prieto L, Sacristán JA, Pinto JL, Badia X, Antoñanzas F, del Llano J, Grupo ECOMED: Analysis of costs and results of the economic assessment of health interventions. Med Clin (Barc) 2004, 122:423-429.

31. Encuesta de costes laborales: Instituto Nacional de Estadística (INE). Available at: http://www.ine.es/infoine.

32. Thompson SG, Barber JA: How should cost data in pragmatic randomised trials be analysed? BMJ 2000, 320:1197-1200.

33. Wetherell $\mathrm{J}$, Unützer J: Adherence to treatment for geriatric depression and anxiety. CNS Spectr 2003, 12(Suppl 3):48-59.

34. Osterberg L, Blaschke T: Adherence to medication. N Engl J Med 2005 353:487-497.

35. Trivedi MH, Lin EH, Katon WJ: Consensus recommendations for improving adherence, self-management, and outcomes in patients with depression. CNS Spectr 2007, 12(Suppl 13):1-27.

36. Hess LM, Raebel MA, Conner DA, Malone DC: Measurement of adherence in pharmacy administrative databases: a proposal for standard definitions and preferred measures. Ann Pharmacother 2006, 40:1280-1288.

37. Kendrick T, Dowrick C, McBride A, Howe A, Clarke P, Maisey S, Moore M, Smith PW: Management of depression in UK general practice in relation to scores on depression severity questionnaires: analysis of medical record data. BMJ 2009, 338:b750.

38. Wang J, Langille DB, Patten SB: Mental health services received by depressed persons who visited general practitioners and family doctors. Psychiatr Serv 2003, 54:878-883.

39. Grembowski DE, Martin D, Patrick DL, Williams B, Diehr P, Martin DP: Managed care, access to mental health specialists, and outcomes among primary care patients with depressive symptoms. J Gen Intern Med 2002, 17:258-269.

40. Piek E, van der Meer K, Penninx BW, Verhaak PF, Nolen WA: Referral of patients with depression to mental health care by Dutch general practitioners: an observational study. BMC Fam Pract 2011, 12:41.

41. Krahn DD, Bartels SJ, Coakley E, Oslin DW, Chen H, Mclntyre J, Chung H, Maxwell J, Ware J, Levkoff SE: PRISM-E: comparison of integrated care and enhanced specialty referral models in depression outcomes. Psychiatr Serv 2006, 57:946-953.

42. Shvartzman $P$, Weiner Z, Vardy D, Friger $M$, Sherf $M$, Biderman A: Health services utilization by depressive patients identified by the MINI questionnaire in a primary care setting. Scand J Prim Health Care 2005, 23:18-25.

43. Simon GE, Revicki D, Heiligenstein J, Grothaus L, VonKorff M, Katon WJ, Hylan TR: Recovery from depression, work productivity, and healthcare costs among primary care patients. Gen Hosp Psychiatr 2000, 22:153-162.

44. Sobocki P, Ekman M, Agren H, Krakau I, Runeson B, Mårtensson B, Jönsson $B$ : Resource use and costs associated with patients treated for depression in primary care. Eur J Health Econ 2007, 8:67-76.

45. Chang TE, Jing Y, Yeung AS, Brenneman SK, Kalsekar I, Hebden T, McQuade $R$, Baer $L$, Kurlander JL, Watkins AK, Siebenaler JA, Fava M: Effect of communicating depression severity on physician prescribing patterns: findings from the Clinical Outcomes in Measurement-based Treatment (COMET) trial. Gen Hosp Psychiatr 2012, 34:105-112.

46. Rush AJ, Trivedi MH, Wisniewski SR, Nierenberg AA, Stewart JW, Warden D, Niederehe G, Thase ME, Lavori PW, Lebowitz BD, McGrath PJ, Rosenbaum 
JF, Sackeim HA, Kupfer DJ, Luther J, Fava M: Acute and longer-term outcomes in depressed outpatients requiring one or several treatment steps: a STAR*D report. Am J Psychiatry 2006, 163:1905-1917.

47. Thase ME: Antidepressant combinations: widely used, but far from empirically validated. Can J Psychiatr 2011, 56:317-323.

48. Souery D, Serretti A, Calati R, Oswald P, Massat I, Konstantinidis A, Linotte S, Bollen J, Demyttenaere K, Kasper S, Lecrubier Y, Montgomery S, Zohar J, Mendlewicz J: Switching antidepressant class does not improve response or remission in treatment-resistant depression. J Clin Psychopharmacol 2011, 31:512-516.

49. Motheral B, Brooks J, Clark MA, Crown WH, Davey P, Hutchins D, Martin BC Stang P: A checklist for retrospective database studies - Report of the ISPOR Task Force on Retrospective Databases. Value Health 2003, 6:90-97.

50. Fernandez-Meza A, Pinto-Meza A, Bellon JA, Roura-Poch P, Haro JM, Autonell J, Palao DJ, Peñarrubia MT, Fernández R, Blanco E, Luciano JV Serrano-Blanco A: Is major depression adequately diagnosed and treated by general practitioners? Results from an epidemiological study. Gen Hosp Psychiatr 2010, 32:201-209.

doi:10.1186/1744-859X-11-22

Cite this article as: Sicras-Mainar et al:: Assessment of pharmacological strategies for management of major depressive disorder and their costs after an inadequate response to first-line antidepressant treatment in primary care. Annals of General Psychiatry 2012 11:22.

\section{Submit your next manuscript to BioMed Central and take full advantage of:}

- Convenient online submission

- Thorough peer review

- No space constraints or color figure charges

- Immediate publication on acceptance

- Inclusion in PubMed, CAS, Scopus and Google Scholar

- Research which is freely available for redistribution 